\title{
CELLULOSE SULFURIC ACID AS A NEW, BIODEGRADABLE AND ENVIRONMENTALLY FRIENDLY BIO- POLYMER FOR SYNTHESIS OF 4,4'-(ARYLMETHYLENE)BIS(3-METHYL-1-PHENYL-1H-PYRAZOL-5-OLS)
}

\author{
ELAHEH MOSADDEGH, ${ }^{a, I^{*}}$ ASADOLLAH HASSANKHANI, ${ }^{a}$ AMIN BAGHIZADEH ${ }^{b}$
}

\begin{abstract}
${ }^{a}$ Department of Materials Science, International Center for Science, High Technology \& Environmental Sciences, P O Box 76315-117, Kerman, Iran
${ }^{b}$ Department of Biotechnology, International Center for Science, High Technology \& Environmental Sciences, P O Box 76315-117, Kerman, Iran.
\end{abstract}

(Received: August 11, 2010 - Accepted: October 11, 2010)

\begin{abstract}
The one-pot multicomponent synthesis of 4,4'-arylmethylene-bis(3-methyl-1-phenyl-1H-pyrazol-5-ol) was performed effectively by tandem KnoevenagelMichael reaction of aryl aldehydes and 5-methyl-2-phenyl-2,4-dihydro-3H-pyrazol-3-one in the presence of a catalytic amount of cellulose sulfuric acid as an environmentally friendly biopolymer-based solid acid catalyst at reflux conditions. All of obtained compounds were characterized by FT IR, ${ }^{1} \mathrm{H}$ and ${ }^{13} \mathrm{C}$ NMR. This new methodology is of interest due to minimizing the cost operational hazards and environmental pollution, high yields, short reaction time, cost effective and simple work-up.
\end{abstract}

Keywords: Cellulose sulfuric acid, biopolymer, 4,4'-(arylmethylene)bis(3-methyl-1-phenyl-1H-pyrazol-5-ols), 5-methyl-2-phenyl-2,4-dihydro-3H-pyrazol3-one, environmentally friendly.

\section{INTRODUCTION}

Green chemistry emphasizes the development of environmentally benign chemical processes and technologies. ${ }^{1}$ Recently, the direction of science and technology has been shifting more towards eco-friendly, natural product resources and reusable catalysts. Thus, natural biopolymers are attractive candidates in the search for such solid support catalysts. ${ }^{2,3}$ Among several reusable and heterogeneous catalysts designed and used in organic reactions, cellulose sulfuric acid (CSA) is one of the useful examples of them, which has been performed as an inexpensive biopolymer-based catalyst that can be easily separated, reused and is not contaminated by the products. ${ }^{4}$

Nowadays, the pyrazolone derivatives were paid much attention for their various biological activities such as antitumor ${ }^{5,6}$ selective COX-2 inhibitory, ${ }^{7}$ cytokine inhibitors. ${ }^{8}$ Moreover, they are capable of prototropic tautomerism. ${ }^{9}$ The compounds that contain two pyrazolone ring can be used as extractant for some metal ions ${ }^{10}$ and ligands. ${ }^{11,1}$ 2,4-Dihydro-3H-pyrazol3-one derivatives including 4,4'-(arylmethylene)bis(3-methyl-1-phenyl- $1 \mathrm{H}$ pyrazol-5-ols) being used as gastric secretion stimulatory ${ }^{13}$ antidepressant, ${ }^{14}$ antibacterial 15 and antifilarial agents. ${ }^{16}$ Moreover, these copmounds are applied as fungicides, ${ }^{17}$ pesticides ${ }^{18}$ insecticides ${ }^{19}$ and dyestuffs. ${ }^{20}$ The conventional chemical approach to 4,4'-(arylmethylene)bis(3-methyl-1-phenyl-pyrazol5 -ols) involves the successive Knoevenagel synthesis of the corresponding arylidenepyrazolones and its base promoted Michael reaction and also one-pot tandem Knoevenagel-Michael reaction of arylaldehydes with two equivalents of 5-methyl-2-phenyl-2,4-dihydro-3Hpyrazol-3-one performed under a variety of reaction conditions. ${ }^{21}$ The first set of procedures utilizes the catalysis of the components with piperidine in ethanolic solution. ${ }^{22}$ The second set of methods involve the noncatalyzed tandem Knoevenagel-Michael reaction under neutral conditions in either ethanol ${ }^{23}$ or benzene ${ }^{24}$ solutions. Although it affords the corresponding 4,4'- (arylmethylene)bis( $1 H$-pyrazol-5-ols) in reliable 70-90 $\%$ yields, the reaction requires 3-12 hours of initial reflux with a further 24 hours under ambient temperature to go to completion. Moreover, synthesis of titled compounds was reported using variety of reagents such as microwave irradiation $^{25}$ triethylbenzylammonium chloride (TEBA), ${ }^{26}$ sodium dodecyl sulfate (SDS), ${ }^{27}$ electrolysis, ${ }^{28}$ cerium(IV) ammonium nitrate (CAN, 5 mol $\%)^{29}$ and Silica-bonded S-sulfonic acid (SBSSA, $0.1 \mathrm{~g}$ ). ${ }^{30}$ However, there are disadvantages to these mentioned methods such as low yield, prolonged reaction time and use of toxic organic solvents, harsh reaction conditions or tedious workup procedures.

Thus, a search for new reagents and the development of new methods are still of practical importance. According to the principle of safe chemistry, synthetic method should be designed to use substances that exhibit little or no toxicity to human health and environment.

In this regard, a novel method to synthesis of 4,4'-(arylmethylene)bis(3methyl-1-phenyl-pyrazol-5-ols) derivatives using 5-methyl-2-phenyl-2,4dihydro-3H-pyrazol-3-one and aromatic aldehydes in the presence of cellulose sulfuric acid as biodegradable and an environmentally friendly catalyst with high catalytic activity and reusability was reported herein.

\section{EXPERIMENTAL}

Melting points were determined on a Gallenkamp melting point apparatus and are uncorrected. NMR spectra were recorded at $500\left({ }^{1} \mathrm{H}\right)$ and $125.77\left({ }^{13} \mathrm{C}\right)$ $\mathrm{MHz}$ on Bruker DRX-500 Avance spectrometer at 500 and $125.77 \mathrm{MHz}$, respectively. All compounds were known in the literature, ${ }^{25-30}$ the NMR and IR spectra of the products were in agreement with earlier data.

Typical reaction procedure for preparation of 4,4'-[(4-chlorophenyl)methylene]bis(3-methyl-1-phenyl-pyrazol-5-ols (Table 1 , entry 3)

A mixture of aromatic aldehyde (1 mmol), 5-methyl-2-phenyl-2,4dihydro-3H-pyrazol-3-one $(2 \mathrm{mmol})$ and cellulose sulfuric acid $(0.2 \mathrm{~g})$ in water-ethanol $(1: 1,5 \mathrm{~mL})$ were added to a flask and heated under reflux conditions for an appropriate time. After the completion of the reaction, as indicated by TLC, the reaction mixture was washed with warm ethanol $(3 \times 30$ $\mathrm{mL}$ ). After cooling, the crude products were precipitated. The crude products were purified by recrystallization from ethanol $(95 \%)$. The recovered catalyst was washed with diethyl ether, dried, and reused for subsequent runs. The structures of the products were confirmed from physical and spectroscopic data such as melting points, IR and ${ }^{1} \mathrm{H}$ NMR spectra. The selected spectral data of two representative compounds are given below:

4,4'-[(phenylmethylene)bis(3-methyl-1-phenyl-1H-pyrazol-5-ol) (Table 1, entry 1)

mp 170-172 ${ }^{\circ} \mathrm{C}$; IR (KBr): 3361(OH), 2927, 1625, 1574(C=C) $\mathrm{cm}^{-1} ;{ }^{1} \mathrm{H}$ NMR (500 MHz, DMSO): $\delta 2.49(\mathrm{~s}, 6 \mathrm{H}, \mathrm{CH}), 4.94(\mathrm{~s}, 1 \mathrm{H}, \mathrm{CH}), 7.15-7.70$ (m, 14H, arom), $12.44(\mathrm{~s}, 1 \mathrm{H}, \mathrm{OH}), 13.98(\mathrm{~s}, 1 \mathrm{H}, \mathrm{OH}) \mathrm{ppm} ;{ }^{13} \mathrm{C}$ NMR $(125.13$ MHz, DMSO): $\delta 11.56,33.14,120.46,125.43,125.78,127.10,128.03,128.13$, $142.28,146.21 \mathrm{ppm}$.

4,4'-[(4-chlorophenyl)methylene]bis(3-methyl-1-phenyl-1H-pyrazol-5-ol) (Table 1, entry 3)

$\mathrm{mp} 213-215^{\circ} \mathrm{C}$; IR $(\mathrm{KBr}) 3463(\mathrm{OH}), 2927,1625,1574(\mathrm{C}=\mathrm{C}) \mathrm{cm}^{-1} ;{ }^{1} \mathrm{H}$ NMR (500 MHz, DMSO): $\delta 2.30(\mathrm{~s}, 6 \mathrm{H}, \mathrm{CH}), 7.22-7.70(\mathrm{~m}, 14 \mathrm{H}$, arom $), 4.95$ $(\mathrm{s}, 1 \mathrm{H}, \mathrm{CH}), 12.50(\mathrm{~s}, 1 \mathrm{H}, \mathrm{OH}), 13.87(\mathrm{~s}, 1 \mathrm{H}, \mathrm{OH}) \mathrm{ppm} ;{ }^{13} \mathrm{C}$ NMR $(125.13$ MHz, DMSO): $\delta 11.50,32.56,120.47,125.51,127.81,128.81,129.04,130.47$, $137.33,141.11,146.15 \mathrm{ppm}$.

Preparation of cellulose sulfuric acid

To a magnetically stirred mixture of $5.0 \mathrm{~g}$ of cellulose) in $20 \mathrm{ml}$ of chloroform, $1.0 \mathrm{~g}$ of chlorosulfonic acid $(9 \mathrm{mmol})$ was added dropwise at $0{ }^{\circ} \mathrm{C}$ during 2 hours. $\mathrm{HCl}$ gas was removed from the reaction vessel immediately. After the addition was complete, the mixture was stirred for 2 hours. The mixture was then filtered and washed with $30 \mathrm{ml}$ of methanol and dried at room temperature to afford cellulose sulfuric acid as a white powder. 


\section{RESULTS AND DISCUSSION}

As a part of our interest in the development of heterocycle-based compounds, ${ }^{31}$ we wish to report the synthesis of 4,4'-(arylmethylene)bis(3methyl-1-phenyl-pyrazol-5-ols) by a cellulose sulfuric acid catalyzed one-pot tandem Knoevenagel-Michael reaction in $\mathrm{H}_{2} \mathrm{O}-\mathrm{EtOH}$ as a green solvent media in reflux conditions with good to excellent yields (74-97\%) (Scheme 1).

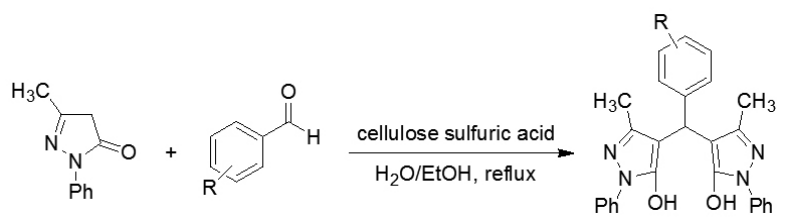

Scheme 1.

Comparison of the reaction time and the yield of corresponding 4,4'-(arylmethylene)bis(3-methyl-1-phenyl-pyrazol-5-ols) with reported conventional chemical approach in the literature was shown, our method is more efficient, requires less time and catalyst loading. . $^{2-28,30}$

In our initial endeavor, we carried out the reaction of 5-methyl-2-phenyl2,4-dihydro-3H-pyrazol-3-one (2 eq) with different aromatic aldehydes (1 eq) using $0.2 \mathrm{~g}$ of cellulose sulfuric acid at reflux conditions. The reaction proceeded to completion and pure product was obtained, without using any chromatographic techniques, simply by recrystallization from ethanol. The reaction condition was optimized by conducting the reaction in different temperatures. With these optimistic results in hand, further investigation was carried out for the catalytic evaluation of cellulose sulfuric acid for the optimum reaction conditions. The best result was obtained by the application of $0.2 \mathrm{~g}$ of cellulose sulfuric acid at reflux conditions in $\mathrm{H}_{2} \mathrm{O}-\mathrm{EtOH}$ as solvent.

The reactions of various aromatic aldehydes under thermal conditions are summarized in Table 1. There is an interesting that the aromatic benzaldehyde having electron-withdrawing groups such as nitro and halide groups undergo smooth cyclo condensation with good to excellent yields of product more efficiency than those have electron-donating groups. Steric hindrance seems to have no significant effects on the yields.

Table 1: Cellulose sulfuric acid catalyzed the synthesis of 4,4 '- (arylmethylene)bis ( 3 - methy $1-1$ - pheny 1 - pyrazol-

\begin{tabular}{|c|c|c|c|}
\hline Entry & $\mathrm{Ar}$ & Time (min) & Yield $(\%)^{\mathrm{a}}$ \\
\hline 1 & $\mathrm{C}_{6} \mathrm{H}_{5}$ & 120 & 74 \\
\hline 2 & $3-\mathrm{Br}^{6}-\mathrm{C}^{5} \mathrm{H}$ & 15 & 86 \\
\hline 3 & 4-Cl- $\mathrm{CH}_{4}$ & 25 & 84 \\
\hline 4 & 4- $\mathrm{CH}_{3} \mathrm{O}-\mathrm{C}_{6} \mathrm{H}_{4}$ & 200 & 84 \\
\hline 5 & $2-\mathrm{Cl}-\mathrm{C}_{6} \mathrm{H}_{4}$ & 20 & 97 \\
\hline 6 & $3-\mathrm{O}_{2} \mathrm{~N}-\mathrm{C}_{6} \mathrm{H}_{4}^{4}$ & 10 & 90 \\
\hline 7 & 4- $\mathrm{HO}^{2}-\mathrm{C}_{6} \mathrm{H}_{4}^{4}$ & 30 & 75 \\
\hline 8 & $3,4,5-\left(\mathrm{CH}_{3} \mathrm{O}\right)_{3}-\mathrm{C}_{6} \mathrm{H}_{2}$ & 40 & 90 \\
\hline 9 & $3-\mathrm{H}_{3} \mathrm{C}-\mathrm{C}_{6} \mathrm{H}_{4}$ & 30 & 75 \\
\hline 10 & $4-\mathrm{H}_{3}^{3} \mathrm{C}-\mathrm{C}_{6}^{\circ} \mathrm{H}_{4}^{4}$ & 120 & 74 \\
\hline 11 & 4-Br- $-\mathrm{C}_{6} \mathrm{H}_{4}^{4}$ & 30 & 90 \\
\hline 12 & $4-\mathrm{HO}-3-\mathrm{CH}_{3} \mathrm{OC}_{6}^{4} \mathrm{H}_{3}$ & 130 & 90 \\
\hline 13 & 3- $\mathrm{Cl}-\mathrm{CH}_{\mathrm{H}}$ & 20 & 90 \\
\hline 14 & $2,4-\mathrm{Cl}_{2}-\mathrm{C}_{6} \mathrm{H}_{3}$ & 25 & 76 \\
\hline 15 & $4-\mathrm{O}_{2} \mathrm{~N}^{2}-\mathrm{C}_{6}^{6} \mathrm{H}_{4}^{3}$ & 10 & 83 \\
\hline
\end{tabular}

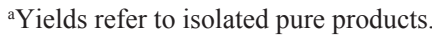

\section{CONCLUSION}

In conclusion, we have demonstrated that cellulose sulfuric acid is a highly efficient catalyst for the synthesis of 4,4'-(arylmethylene)bis(3-methyl1-phenyl-pyrazol-5-ols) derivatives in reflux conditions and low catalyst loading $(0.2 \mathrm{~g})$. In addition moisture compatibility of the catalyst, good to excellent yields of products, short reaction time, simple experimental and isolation procedures make this methodology a valid contribution to the existing processes in the field of 4,4'-(arylmethylene)bis(3-methyl-1-phenyl-pyrazol-5ols) derivatives synthesis. The process does not require the use of any volatile organic solvent, harmful metal catalyst and thus, is a simple, cleaner, costeffective, easy, environmentally friendly and safety reaction.

\section{REFERENCES}

[1] (a) P. T. Anastas and J. C. Warner, Green Chemistry: Theory and Practice; Oxford University Press, Oxford, UK, 1998; (b) P. T. Anastas and T. Williamson, Green Chemistry, Frontiers in Benign Chemical Synthesis and Process; Oxford University Press, Oxford, UK, 1998.

[2] T. Hideo, Chem. Abstr. 95 (1981) 80922b, Jpn. Tokyo Koho JP, (1981) 56005480 .

[3] J. P. Poupelin, G. Saint-Ruf, O. Foussard-Blanpin, G. Narcisse, G. Uchida-Ernouf and R. Lacroix, Eur. J. Med. Chem. 13 (1978) 67.

[4] (a) A. Shaabani, A. Rahmati and Z. Badri, Catal. Commun. 9 (2008) 13; (b) A. Shaabani and A. Maleki, Appl. Catal. A: Gen. 331 (2007) 149; (c) H. Alinezhad, A. Hagh Haghighi and F. Salehian, Chin. Chem. Lett. 21 (2010) 183; (d) A. Shaabani, M. Seyyedhamzeh, A. Maleki and F. Rezazadeh, Appl. Catal. A: Gen. 358 (2009) 146.

[5] H. -J. Park, K. Lee, S. -J. Park, B. Ahn, J. -C. Lee, H. Y. Cho and K. -I. Lee, Bioorg. Med. Chem. Lett. 15 (2005) 3307.

[6] M. P. Clark, S. K. Laughlin, M. J. Laufersweiler, R. G. Bookland, T. A. Brugel, A. Golebiowski, M. P. Sabat, J. A. Townes, J. C. VanRens, J. F. Djung, M. G. Natchus, B. De, L. C. Hsieh, S. C. Xu R. L. Walter, M. J. Mekel, S. A. Heitmeyer, K. K. Brown, K. Juergens, Y. O. Taiwo and M. J. Janusz, J. Med. Chem. 11 (2004) 2724.

[7] I. H. Cho, J. Y. Noh, S. W. Park, H. C. Ryu, J. W. Lim, J. H. Kim, M. Y. Chae, D. H. Kim, S. H. Jung, H. J. Park, Y. H. Kim and I. K. Min, US Patent. 2, 004, 002, 532, (2004).

[8] M. P. Clark, S. K. Laughlin, A. Golebiowski, T. A. Brugel and M. Sabat, WO Patent. 2, 005, 047, 287, (2005).

[9] Akama Y and Tong A. Microchem. J. 53 (1996) 34.

[10] H. Takeishi, Y. Kitatsuji, T. Kimura, Y. Meguro, Z. Yoshida and S. Kihara, Anal. Chim. Acta. 1 (2001) 69

[11] S. A. Abdel-Latif, Synth. React. Inorg. Metal-organic Chem. 8 (2001) 1355.

[12] C. Pettinari, F. Marchetti, R. Pettinari, D. Martini, A. Drozdov and S. Troyanov, J. Chem. Soc., Dalton Trans. 11 (2001) 1790.

[13] C. E. Rosiere and M. I. Grossman, Science. 113 (1951) 651.

[14] D. M. Bailey, P. E. Hansen, A. G. Hlavac, E. R. Baizman, J. Pearl, A. F. Defelice and M. E. Feigenson, J. Med. Chem. 28 (1985) 256.

[15] R. N. Mahajan, F. H. Havaldar and P. S. Fernandes, J. Indian Chem. Soc. 68 (1991) 245.

[16] P. M. S. Chauhan, S. Singh and R. K. Chatterjee, Indian J. Chem. Sect., B: Org. Chem. Incl. Med. Chem. 32 (1993) 858.

[17] D. Singh and D. Singh, J. Indian Chem. Soc. 68 (1991) 165.

[18] M. Londershausen, Pestic. Sci. 48 (1996) 269.

[19] H. A. Lubs, The Chemistry of Synthetic Dyes and Pigments; Eds. American Chemical Society, Washington D.C., 1970.

[20] (a) A. B. Uzoukwu, Polyhedron. 12 (1993) 2719; (b) R. C.; Maurya and R. Verma, Indian J. Chem., Sect. A 36 (1997) 596; (c) A. D. Garnovskii, A. I. Uraev and V. I. Minkin, Arkivoc. (iii), 29 (2004) 23.

[21] (a) W. S. Hamama, Synth. Commun. 31 (2001) 1335; (b) X. -L. Li, Y. -M. Wang, B.Tian, T. Matsuura and J. -B. Meng, J. Heterocycl. Chem. 35 (1998) 129

[22] (a) D. Singh and D. Singh, J. Chem. Eng. Data. 29, 355, (1984); (b) A. S. Mitra and M. K. Rout, J. Indian Chem. Soc. 38 (1961) 893.

[23] P. T. Pavlov, A. F. Goleneva, A. E. Lesnov and T. S. Prokhorova, Pharm. Chem. J. (Engl. Transl.) 32 (1998) 370.

[24] B. I. Buzykin and T. I. Lonshchakova, Bull. Acad. Sci. USSR, Div. Chem. Sci. (Engl. Transl.) (1971) 2224.

[25] Y. -J. Bai, J. Lu, Z. -J. Wang, H. -Y. Gan and H. -R. Ma, Chin. J. Org. Chem. (in Chinese) 6 (2004) 616.

[26] D. -Q. Shi, J. Chen, N. Wu, Q.-Y. Zhuang and X. -S. Wang, Chin. J. Org. Chem. 4 (2005) 405.

[27] W. Wang, S.-X. Wang, X.-Y. Qin and J.-T. Li, Synth. Commun. 9 (2005) 1263.

[28] M. N. Elinson, A. S. Dorofeev, R. F. Nasybullin and G. I. Nikishin, Synthesis. 12 (2008) 1933.

[29] K. Sujatha, G. Shanthi, N. P. Selvam, S. Manoharan, P. T.Perumal and M. Rajendran, Bioorg. Med. Chem. Lett. In Press, 19 (2009) 4501.

[30] D. Niknam, D. Saberi, M. Sadegheyan and A. Deris, Tetrahedron Lett. 51 (2010) 692 .

[31] E. Mosaddegh and M. R. Islami, Org. Prep. Proc. Int. 40 (2008) 586.

[32] (a) E. Mosaddegh, M. R. Islami and A. Hassankhani, Lett. Org. Chem. 4 (2007) 524; (b) M. R. Islami and E. Mosaddegh, Phosphorus, Sulfur Silicon Relat. Elem. 184 (2009) 3134. 5-ols) derivatives. 